УДК 336.2

JEL Classification: $\mathrm{H} 20$

\title{
ТРАНСФОРМАЦИЯ НАЛОГОВЫХ СИСТЕМ НА ПРИМЕРЕ СТРАН - ЧЛЕНОВ ЕВРОПЕЙСКОГО СОЮЗА
}

\author{
DOI: 10.32620/cher.2018.4.05
}

Постановка проблемы. Благополучие и эффективность функционирования экономики страны во многом зависит от состояния ее налоговой системы, на которую оказывают огромное влияние переменчивые экономические условия, развитие внешнеторговых связей, активные процессы интеграции и глобализации. Современная налоговая система должна соответствовать стандартам экономики мирового пространства и опираться на реалии экономического развития и специфику страны. Цель статьи - провести анализ трансформаций налоговых систем стран Европейского Союза в рамках консолидации его внутренней политики в кризисный период и оценить эффективность принятых мер. Объект исследования - налоговые системы стран Европейского Союза представляет собой объединение стран с различным уровнем экономического развития. Meтоды, использованные в исследовании. Применение метода индукции позволило обозначить направления совершенствования налоговой системы Европейского Союза как единого механизма путем консолидации изменений в отдельных странах. Этот опыт сделал возможным выделить страны, которые проводили аналогичные мероприятия, и оценить эффективность реализации реформ. Гипотеза исследования. Функционирование внутреннего рынка Европейского Союза зависит от наличия единого налогообложения всех транзакций внутри него, что обеспечивает свободное обращение товаров и услуг и предотвращает дискриминацию. Изложение основного материала. Многие направления внутренней политики Европейского союза являются перераспределительными по своей природе (единая денежно-кредитная, валютная, сельскохозяйственная, социальная и региональная политика) и зависят от общей бюджетной политики. Оригинальность и практическое значение исследования состоит в обосновании того, что основой валютного союза должна быть скоординированная фискальная политика, требующая множество трансформаций. В действительности это означает, что налоговая среда Европейского Союза не полностью гармонизирована, но основана на единых принципах. Bblводы исследования. Изучение практики реформирования налоговых систем стран - членов Европейского Союза в кризисный период дает возможность оценить возможности трансформации элементов налогообложения и определить наиболее благоприятные тенденции в данной сфере.

Ключевые слова:

налоговая системы, налоговая база, налоговая ставка, налоговый вычет, льгота, реформа.

\section{TRANSFORMATION OF TAX SYSTEMS ON THE EXAMPLE OF THE COUNTRIES - MEMBERS OF THE EUROPEAN UNION}

Formulation of the problem. The well-being and efficiency of the country's economy depends largely on the state of its tax system, which is greatly influenced by changeable economic conditions, the development of

${ }^{1}$ Києвич Олексанр Володимирович, д-р екон. наук, професор кафедри «Фінанси», Полеський державний університет, м. Пінськ, Республіка Білорусь.

Kievich Aleкsandr, Professor, Ph.D. in Economics, Professor of Finance Department Polessky state University, Pinsk, Republic of Belarus.

ORCID ID: 0000-0003-4249-7644

e-mail: a.v.kievich@yandex.ru

${ }^{2}$ Пригодич Ірина Олександрівна, канд. екон. наук, доцент кафедри ««Фінанси», Полеський державний університет, м. Пінськ, Ре-спубліка Білорусь.

Prigodich Irina, Ph.D. in Economics, Associate Professor of Finance Department Polessky state University, Pinsk, Republic of Belarus.

ORCID ID: 0000-0002-7249-4690

e-mail: Prigodich.Ira@yandex.ru

${ }^{3}$ Конончук Ірина Анатоліївна, канд. екон. наук, доцент кафедри ««Фінанси», Полеський державний університет, м. Пінськ, Республіка Білорусь.

Kononchuk Irina, Ph.D. in Economics, Associate Professor of Finance Department Polessky state University, Pinsk, Republic of Belarus.

ORCID ID: 0000-0003-2734-2812

e-mail: i_kononchuk@mail.ru 
foreign trade, and active processes of integration and globalization. The modern tax system must meet the standards of the economy of the world and rely on the realities of economic development and the specifics of the country. The aim of the research is to analyze the transformations of the tax systems of the European Union within the framework of the consolidation of its domestic policy during the crisis period and to evaluate the effectiveness of the measures taken. The object of the research is tax systems of the European Union is an association of countries with different levels of economic development. Methods used of the research. The use of the induction method allowed us to designate directions for improving the tax system of the European Union as a single mechanism by consolidating changes in individual countries. This experience made it possible to identify countries that carried out similar activities, and to assess the effectiveness of the implementation of reforms. The hypothesis of the research.The functioning of the internal market of the European Union depends on the existence of a single tax on all transactions within it, which ensures the free circulation of goods and services and prevents discrimination. The statement of basic materials. Many European Union domestic policies are redistributive in nature (single monetary, monetary, agricultural, social and regional policies) and depend on a common fiscal policy. Originality and practical significance of the research is to justify that the basis of a monetary union should be a coordinated fiscal policy that requires many transformations. In fact, this means that the tax environment of the European Union is not fully harmonized, but is based on common principles. Conclusions of the research. The study of the practice of reforming the tax systems of the countries - members of the European Union during the crisis period makes it possible to assess the possibilities of transforming the elements of taxation and to determine the most favorable trends in this area.

Key words:

tax system, tax base, tax rate, tax deduction, exemption, reform.

\section{ТРАНСФОРМАЦІЯ ПОДАТКОВИХ СИСТЕМ НА ПРИКЛАДІ КРАЇН - ЧЛЕНІВ ЄВРОПЕЙСЬКОГО СОЮЗУ}

Постановка проблеми. Благополуччя і ефективність функціонування економіки країни багато в чому залежить від стану іiі податкової системи, на яку впливають мінливі економічні умови, розвиток зовнішньоторговельних зв'язків, активні процеси інтеграції та глобалізації. Сучасна податкова система повинна відповідати стандартам економіки світового простору і спиратися на реалії економічного розвитку і специфіку країни. Мета статmі - провести аналіз трансформацій податкових систем країн Європейського Союзу в рамках консолідації його внутрішньої політики в кризовий період і оцінити ефективність вжитих заходів. Об'єкт дослідження - податкові системи країн Європейського Союзу є об'єднання країн з різним рівнем економічного розвитку. Методи, використані в дослідженні. Застосування методу індукції дозволило окреслити напрямки вдосконалення податкової системи Свропейського Союзу як єдиного механізму шляхом консолідації змін в окремих країнах. Цей досвід зробив можливим виділити країни, які проводили аналогічні заходи, і оцінити ефективність реалізації реформ. Гіпотеза дослідження. Функціонування внутрішнього ринку Європейського Союзу залежить від наявності єдиного оподаткування всіх транзакцій всередині нього, що забезпечує вільний обіг товарів і послуг і запобігає дискримінацію. Виклад основного матеріалу. Багато напрямів внутрішньої політики Свропейського союзу є перерозподільними за своєю природою (єдина грошово-кредитна, валютна, сільськогосподарська, соціальна і регіональна політика) і залежать від загальної бюджетної політики. Оригінальність $і$ практичне значення дослідження полягає в обгрунтуванні того, що основою валютного союзу повинна бути скоординована фіскальна політика, що вимагає безліч трансформацій. Насправді це означає, що податкове середовище Європейського Союзу не повністю гармонізована, але заснована на єдиних принципах. Висновки дослідження. Вивчення практики реформування податкових систем країн - членів Свропейського Союзу в кризовий період дає можливість оцінити можливості трансформації елементів оподаткування і визначити найбільш сприятливі тенденції в даній сфері.

Ключові слова:

податкова системи, податкова база, податкова ставка, податкові відрахування, пільга, реформа.

Постановка проблемы. В настоящее время Европейский союз является одним из наиболее крупных интеграционных образований в мире, которое реализует единую экономическую политику, в том числе и в области налогообложения. Создание общего европейского рынка, конкурентоспособного на мировой арене, подразумевает обеспечение равных условий осущест- вления торговых транзакций для субъектов хозяйствования всех стран-членов Европейского Союза. Для успешной реализации идеи общего рынка устраняются все препятствия, в том числе и налоговые путем гармонизации налогового законодательства. Мировой финансовый кризис 2008-2010 годов усложнил и замедлил унификацию налоговых систем стран Европейского 
Союза и позволил странам адаптировать свои налоговые системы согласно выявленным проблемам. В последствии опыт стран-членов Европейского Союза позволил провести компаративный анализ налоговых реформ в странах с различным экономическим состоянием и обозначить их ключевые недостатки.

Анализ последних исследований и публикаций. Вопросами развития налоговой системы, налоговой политики, налогового менеджмента, а также методами и инструментами его реализации занимались такие ученые как А. Смит, Д. Рикардо, А. В. Брызгалин, Б. А. Рогозин, Д. Г. Черник. Среди белорусских ученых, исследующих аспекты налогообложения можно отметить Т. И. Василевскую, Т.А. Верезубову, Н. Е. Заяц, Е.Ф. Кирееву.

Цель статьи - провести анализ трансформаций налоговых систем стран
Европейского Союза в рамках консолидации его внутренней политики в кризисный период и оценить эффективность принятых мер.

Изложение основного материала исследования. В условиях преодоления последствий мирового финансового кризиca $[1,2]$, который привел к дестабилизации денежно-кредитной политики стран $[3,4]$ и нестабильности макроэкономических показателей необходимо рассмотреть основные положения, предусмотренные налоговыми реформами многих стран, а также изменения, которые произошли в фискальной политике некоторых стран, входящих в состав Европейского союза, в период финансового кризиса 2008-2010 годов.

Все предпринятые в странах меры по трансформации налоговых систем призваны сократить налоговую нагрузку, которая с 2004 года начала возрастать [5] (Рис. 1).

42

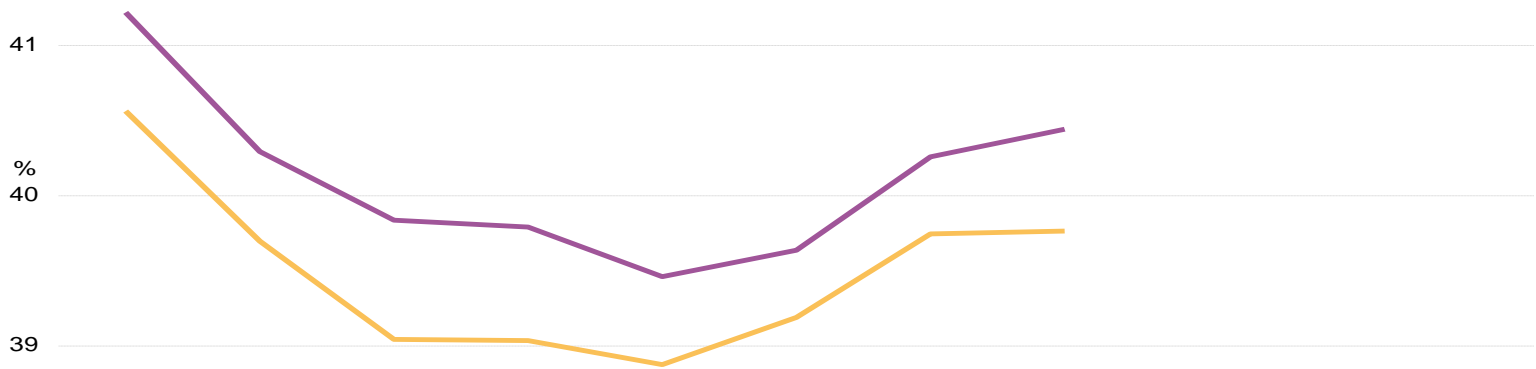

38

\begin{tabular}{|c|c|c|c|c|c|c|c|c|c|c|}
\hline 2000 & 2001 & 2002 & 2003 & 2004 & 2005 & 2006 & 2007 & 2008 & 2009 & 2010 \\
\hline
\end{tabular}

Рис. 1. Динамика реальной налоговой нагрузки в Европейском Союзе, \% от ВВП Источник: разработано авторами

Изменения в налоговых системах стран в большинстве случаев были связаны с манипулированием НДС и акцизами [6-8].

Это было обусловлено тем, что доля налогов на потребление занимала значительное место в структуре налогообложения в предкризисный период [5] (Рис. 2).

Стоит отметить, что налоговая политика в странах - членах Европейского Союза базируется на принципе разумности налогов, а все проведенные трансформации направлены на стимулирование предпринимательской деятельности и расширение налоговых льгот, которые способствуют совокупному спросу и повышают эффективность экономики.

Наиболее значимые изменения касались освобождения от уплаты налогов и расширением диапазона налоговых вычетов.

Согласно закону 2009 г. «О налоговой реформе» в Австрии было предусмотрено ежегодное сокращение налоговой нагрузки приблизительно на 3 миллиарда евро ежегодно $(1,1 \%$ ВВП). Данная реформа предусматривала следующее [5]: 


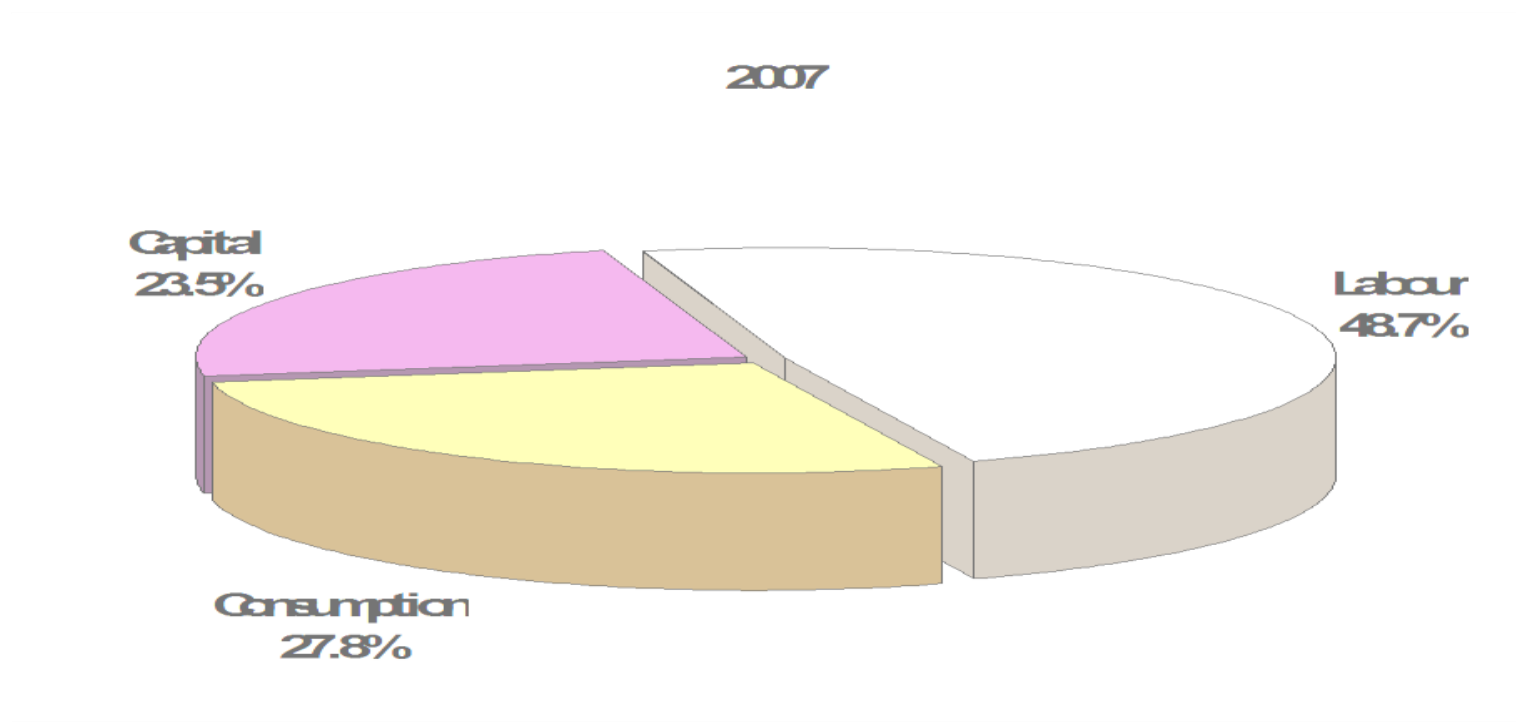

Рис. 2. Структура налогообложения в Европейском Союзе в 2007 году Примечание: Capital - Капитал, Labour - Труд, Consumption - Потребление Источник: разработано авторами

1. Изменения в системе подоходного налога (2,3 миллиарда евро): были понижены крайние границы ставок налога;

2. Введение семейного пакета освобождения от уплаты подоходного налога $(0,5$ миллиарда евро): увеличение детских пособий и налоговых скидок, связанных с наличием в семье ребенка;

3. Увеличение налоговых пособий на предприятиях от $10 \%$ до $13 \%$ с 2010 года. Увеличение объемов инвестиций до $30 \%$ в течение 2009 и 2010 годов (0,7 миллиарда евро).

В Бельгии предприняты следующие меры:

1. Временно продлены сроки уплаты удержаний из заработной платы;

2. Сокращены ставки НДС с $21 \%$ до $6 \%$ для строительства частного (более 50000 евро) и социального жилья;

3. Увеличены общие вычеты для расчета удержаний из заработной платы с $0,25 \%$ до $0,75 \%$ с 1 июня 2009 и до $1 \%$ с 1 января 2010;

4. Увеличено количество сверхурочных часов, по которым предусмотрены уменьшенные удержания заработной платы, с 65 часов до 100 часов в 2009 г. и к 130 часам в 2010 г.

В Болгарии были введены 5-летние налоговые льготы для инвестиций, принимаемых на определенных условиях, для развития сельского хозяйства, а также обрабатывающей промышленности и промышленности, основанной на высоких технологиях, и для создания инфраструктуры. Данные налоговые льготы выступают в качестве государственной помощи и одобрены Европейской Комиссией. Вместе с тем были отменены процентные выплаты по закладным для молодых семей [5].

Реформирование налоговой системы Кипра состояла из следующих мер:

1. Уменьшены ставки акциза для полуправительственных организаций с $25 \%$ до $10 \%$;

2. Временно сокращена на 3 процентных пункта до 5 \% ставка НДС для гостиниц;

3. Уменьшен земельный налог аэропортов, уплачиваемый авиакомпаниями, и отменена уплата земельного налога с территорий, занимаемых ночными стоянками, наложенного местными органами властями.

Чешская Республика ускорила обесценивание специфических активов, снизила ставку НДС для трудоемких услуг и полностью отменила НДС на приобретение легковых автомобилей для предпринимателей.

Правительство Дании инициировало главную налоговую реформу, которая осуществляется постепенно с 2010 до 2019 года. Ее основными положениями являются:

1. Изменение сроков уплаты НДС и отмена подоходного налога;

2. Увеличение налоговой льготы на производственную прибыль с 4 \% до 4,25 \%.

В Эстонии сократили ставку НДС на 9 процентных пунктов и уменьшили диапазон 
товаров, к которым применялся льготный тариф. Вместе с тем сократили ставки подоходного налога на 1 процентный пункт и увеличили ежегодное личное пособие.

Финляндия увеличила размер акциза на алкоголь и табак на $10 \%$, уменьшила пенсионный сбор в национальный пенсионный фонд, уплачиваемый работодателями на 0,8 процентных пункта с 1 апреля 2009 г., уменьшила ставки НДС на продовольственные товары с $17 \%$ до $12 \%$ с 1 октября 2009 г., ввела новый трудовой кредит по подоходному налогу, предоставляемый для работников с низким и средним заработком, и увеличила налоговые льготы по доходу, полученному по работе на дому до 3000 евро на одного человека.

Во Франции освободили все инвестиции от местного налога на оборудование и налога на собственность с 23 октября 2008 до 31 декабря 2009 года, чем увеличили конкурентоспособность французских компаний, путем сокращения налогового бремени на инвестиции, а также с 1 июля 2009 года была уменьшена ставка НДС до 5,5\% на услуги ресторана.

Германия увеличила ставку налога на услуги домашнего ремонта, осуществляемые работниками по договору найма, до 20 \% от 6 000 евро (то есть минимально 1200 евро), а также внедрила ряд стимулов для покупателей безвредных для окружающей среды автомобилей [5].

Греция в кризисный период внесла корректировки в налоговую систему:

1. Введен дополнительный налог на личный доход для работников с высоким заработком (доход выше 60000 евро в год). Налог постепенно увеличивался с 1000 евро - за доход между 60001 евро и 80000 евро в год и до 25000 евро - за доход свыше 900 000 евро в год;

2. Введена специальная дотация в 500 евро безработным людям или пенсионерам с низким доходом, которые заключили договор кредита в марте 2009 г.;

3. Сокращена с $2,0 \%$ до $0,5 \%$ ставка налога местных властей на доход от деятельности гостиниц, мотелей, бунгало, а также доход ресторанов, клубов, баров, и т.д.;

4. Приостановлены банковские выплаты в размере 0,6 \% по кредитам гостиниц и другим подобным типам услуг на 2009 г.
5. Сокращен налог, который облагает автомобильную регистрацию, на 50 \% в течение апреля-августа 2009 г.

В Венгрии подоходный налог уменьшили, в то время как налоги на потребление и капитал увеличили. С 1 июля 2009 года общая ставка НДС увеличена с 20 \% до $25 \%$ и временно с августа 2009 года уменьшена до $18 \%$ ставка НДС для молочных продуктов, выпечки и теплоцентрали [5].

Ирландия осуществила следующие изменения в налоговой системе:

1. Введен налог на доходы по ставке $1 \%$ на доход до 100100 евро в год и ставке $2 \%$ на доход, превышающий указанную сумму. На доходы сверх 250120 евро в год ставка налога увеличивается на 1 процентный пункт. Платежи социального обеспечения были исключены из данного налога;

2. С 1 мая 2009 года ставки налога на доходы удвоены к 2\%, 4 \% и $6 \%$. Ставка в размере $4 \%$ относится к доходу сверх 75036 евро и $6 \%$ - к доходу сверх 174980 евро;

3. Сокращена ставка гербового сбора с $9 \%$ до $6 \%$;

4. Увеличена ставка НДС с $21 \%$ до $21,5 \%$ в декабре 2008 года.

5. Повышены стандартные налоговые вычеты до 1000 евро на одного человека, и до 2000 евро для женатой пары с 2 доходами;

6. С 8 апреля 2009 года увеличен налог на доходы по депозитам с 23 \% до 25\%.

В Италии сократили ставку акциза на газ для промышленного использования и ряд налогов для операторов дорожной перевозки. В стране ввели налоговые стимулы для покупок бытовой техники и мебели и существенно сократили налоги на жилье.

В Латвии реформа налоговой системы была направлена на увеличение налоговых ставок. В стране возросла ставка НДС с $18 \%$ до $21 \%$ и льготной ставка НДС с $5 \%$ до $10 \%$ Различные типы товаров исключены из перечня льготного налогообложения. Аналогичная тенденция наблюдалась и по акцизу: с января 2009 года была увеличена ставка акциза на сигареты и с февраля 2009 года - на топливо, табак, кофе, алкоголь и безалкогольные напитки.

Литва также как и Латвия пошла по пути увеличения налоговых ставок. Возросла не только ставка акциза на топливо, алкоголь и сигареты, но и ставка НДС на один процентный пункт до $19 \%$. Вместе с тем были отменены ставка НДС $9 \%$, относящаяся к строи- 
тельным услугам, и льготная ставка 5 \%. Однако в стране ввели существенные инвестиционные стимулы в течение периода до 2013 года.

Люксембург провел политику преобразования освобождения от уплаты налога в налоговые льготы и расширил до 80 \% диапазон освобождения от уплаты налогов на доходы и прибыль по доходам, получаемым как с прав по интеллектуальной собственности, так и по доходам от интернет-доменных имен.

В Мальте расширили льготы по отношению к НДС на услуги учреждений культуры и по отношению к налогу на регистрацию грузовиков. Также в стране отменили налог с дорог.

В Нидерландах изменения налоговой системы затронули следующие аспекты:

1. Владельцев топливосберегающих автомобилей освободили от уплаты налога на автомобили, а владельцам автомобилей на природном газу данный налог уменьшили. Для автомобилей, использующих водород, ввели освобождение от налога;

2. Предусмотрели субсидии для утилизации старых автомобилей;

3. Отменили налог на авиабилеты;

4. Компаниям предоставили возможность уплачивать НДС ежеквартально вместо ежемесячно уплаты;

5. Ввели необлагаемый минимум до 3 000 евро для служащих, работающих после достижения 62-ухлетнего возраста;

6. Ввели многочисленные административные упрощения в системе социального обеспечения;

7. Увеличили налоговые льготы для работающих родителей.

В Польше предусмотрено сокращение периода возмещения НДС со 180 до 60 дней и возмещение НДС по безнадежной задолженности сроком более 180 дней налоговыми органами. Также в стране усилили мотивацию к инвестированию, внедрив механизм ускоренной амортизации определенных видов основных фондов для небольших и недавно зарегистрированных юридических лиц.

В Португалии освободили от налогообложения доход, связанный с предоставлением жилищно-коммунальных услуг, а также услуг образования, здравоохранения и санаторно-профилакторного лечения. В стране снизили налоговую ставку по налогу на недвижимость и увеличили период освобождения от его уплаты [5].
Румыния осуществила многочисленные изменения в налоговой системе страны, основными из которых являются:

1. Сокращение ставки НДС с $19 \%$ до $5 \%$ для строительства социального жилья;

2. Увеличение размера вычета по добровольному страхованию от болезней (с 200 евро до 250 евро), а также платежей работников в программы пенсионного обеспечения (с 200 евро до 400 евро);

3. Увеличение акциза на алкогольные напитки, сигареты и топливо с апреля 2009 года;

4. Установление налоговой ставки $2 \%$ на доход, получаемый от сельскохозяйственной деятельности;

5. Временное освобождение от налога на прибыль дохода, получаемого от торговли ценными бумагами на румынском фондовом рынке;

6. Сокращение налога на дивиденды нерезидентов с $16 \%$ до $10 \%$.

Словакия также провела реформу налоговой системы и внесла следующие корректировки:

1. Введен налоговый вычет на работника в максимальном размере 181,03 евро ежегодно;

2. Уменьшена ставка взноса в Агентство Социального страхования с $4,75 \%$ до $2 \%$ для работников, осуществляющих трудовую деятельность не по договору найма;

3. Сокращен период уплаты НДС с 60 дней до 30 дней;

4. Упрощено ведение налоговых записей для небольших юридических лиц.

В Словении увеличили инвестиционный вычет юридическим лицам, вкладывающим капитал в оборудование или нематериальные активы и осуществляющим деятельность в сфере лесного хозяйства и лесоводства. Одновременно был увеличен акциз на бензин, газ, нефть и алкогольные напитки, чтобы обеспечить устойчивый приток общественных доходов. В мае 2009 года последовало увеличение акциза и на табачные изделия.

Испания временно отменила налог на капитальные трансферты, сократила процентную ставку по просроченным налоговым платежам и предоставила дополнительную налоговую льготу в 400 евро для работников, осуществляющих трудовую деятельность не по договору найма. 
Налоговая реформа в Швеции в большинстве случаев касалась изменения льгот. В частности была увеличена сумма минимального личного дохода налогоплательщиков в возрасте старше 65 лет, которая не облагается подоходным налогом, и введена налоговая льгота для реконструкции, модернизации и материально-технического обеспечения строительства домашних хозяйств [5].

Соединенное Королевство Великобритании приняло ряд изменений в налоговой политике, которые носили временный характер:

1. С апреля 2010 года введена дополнительная ставка подоходного налога в размере $50 \%$ от имеющейся ставки в отношение доходов, превышающих 150000 фунтов стерлингов;

2. Сокращена ставка НДС с $17,5 \%$ до $15 \%$ с 1 декабря 2008 года до 31 декабря 2009 года;

3. Исключены из налоговой базы по земельному налогу и гербовому сбору суммы, на которые были приобретены ценности в частную собственность, но не более чем на сумму 175000 фунтов стерлингов в период между сентябрем 2008 года и концом 2009 года.

В Норвегии были увеличены налоговые льготы для компаний, участвующих в научно-исследовательских проектах, одобренных Советом Исследования Норвегии.

Принятые в сфере налогообложения меры в странах Европейского Союза не принесли ожидаемого эффекта. В последующие годы налоговая политика каждой страны корректировалась неоднократно, а основными рычагами воздействия на налоговые системы были воздействия на размер налоговых ставок и манипулирование налоговыми льготами.

Выводы и перспективы далнейших исследований. Анализ проведенных реформ налоговых систем стран-членов Европейского Союза позволяет свидетельствовать о том, что национальные налоговые системы стран неоднородны и не являются полностью сопоставимыми и гармонизированными. Данная ситуация подтверждается и различными результатами проведенных реформ: в странах с более сильной финансовой системой экономика была стабилизирована, однако в странах, финансовая система которых была дестабилизирована еще до 2008 года, реформы лишь усугубили проблемы в их экономи- ке. Разнонаправленность принятых решений и отсутствие единых целевых параметров в налоговой политике сигнализирует о рассогласованности бюджетной, валютной и внешнеэкономической политики.

Подобного рода дифференциация приводит к трудностям реализации перераспределительных процессов, так как таргетирование различных показателей дестабилизирует банковскую систему и повышает банковские риски, максимизация которых негативно влияет на финансовую систему стран с неустойчивой экономикой и позитивно - на финансовую систему стран со стабильной экономикой. Своевременное диагностирование рисков в кредитно-финансовой организации [9] требует комплексного подхода с учетом интеграции всех финансовых аспектов в экономике $[10,11]$ и является трудоемким процессов.

Реализация банковских рисков усугубила проблемы в бюджетной системе ряда стран-членов Европейского Союза, что и потребовало в дальнейшем более радикальных трансформаций в их налоговых системах. Однако стоит отметить, что последствия финансового кризиса спустя десятилетие еще заметны в экономиках большей половины стран Европейского Союза и их нивелирование продолжается и в настоящее время.

\section{Литература}

1. Киевич А. В. Главная причина - сам механизм глобального экономического кризиса : монография / А.В. Киевич. - СанктПетербург : «Инфо-да», 2012. - 236 с.

2. Киевич А. В. ЕАЭС: макроэкономическая стабилизация в условиях глобального кризиса / А. В. Киевич, О. В. Король // Экономика и банки. - 2017. - № 1. - С. 26-34.

3. Киевич A. B. Денежно-кредитная политика: рестрикция и экспансия в переходный период / А. В. Киевич, И. А. Конончук, И. А. Пригодич // Економічний форум. 2018. - № 2. - С. 290-297.

4. Киевич A. В. Дедолларизация мировой экономики как объективная реальность / А.В. Киевич // Вопросы экономики и права. 2017. - № 108. - C. 33-37.

5. Taxation trends in the European Union - 2009 : стат. отчет / Европейский Союз, 2009. $-391 \mathrm{c}$

6. Кисель И. А. Анализ применяемых в практике показателей результативности на- 
логового менеджмента на предприятии / И. А. Кисель // Экономика и банки. - 2014. - № 2. - C. 3-9.

7. Конончук И. А. Организация налогового менеджмента в корпорациях США / И.А. Конончук // Экономика и банки. -2016. - № 2. - С. 20-26.

8. Конончук И. А. Освобождение от налогообложения в условиях зачетного метода расчета НДС / И. А. Конончук // Экономика и банки. - 2018. - № 1. - С. 19-24.

9. Пригодич И. А. Банковский риск: сущность, методика оценки, управление / И. А. Пригодич // Экономика и управление. 2012. - № 4. - С. 85.

10. Пригодич И. А. Развитие интегрированной системы диагностики банковских рисков как актуальное направление совершенствования диагностики в банках / И. А. Пригодич // Экономический бюллетень Научно-исследовательского института Министерства экономики Республики Беларусь. 2014. — № 9. - С. 28-35.

11. Пригодич И. А. Ключевые проблемы ранней диагностики рисков в банках и пути ее совершенствования / И. А. Пригодич // Экономика и банки. - 2014. - № 2. - С. 26-33.

\section{References}

1. Kievich, A. V. (2012). The main reason - the mechanism of the global economic crisis. Sankt-Peterburg, SPB: Info-da, 236.

2. Kievich, A. V. (2017). EEU: macroeconomic stabilization in the context of the global crisis. Economics and banks, 1, 26-34.

Стаття надійшла

до редакції : 08.09.2018 p.
3. Kievich, A. V. \& Kononchuk, I. A. \& Prigodich, I. A. (2018). Monetary policy: restruction and expansion during the transition period. Economic forum, 2, 290-297.

4. Kievich, A. V. (2017). Dedollarization of the world economy as an objective reality. Economic and legal issues, 108, 3337.

5. Taxation trends in the European Union -2009 : stat. otch. (2009). European Union, 391.

6. Kisel, I. A. (2014). Analysis of the tax management indicators used in practice at the enterprise. Economics and banks, 2, 3-9.

7. Kononchuk, I. A. (2016). Organization of tax management in US corporations. Economics and banks, 2, 20-26.

8. Kononchuk, I. A. (2018). Tax exemption in the conditions of the credit method of VAT calculation. Economics and bank, 1, 1924.

9. Prigodich, I. A. (2012). Bank risk: essence, method of assessment, management. Economics and management, 4,85 .

10. Prigodich, I. A. (2014). Development of the integrated system of banking risks diagnostics as an actual direction of diagnostics improvement in banks. Economic Bulletin of the Research Institute of the Ministry of economy of the Republic of Belarus, 9, 28-35.

11. Prigodich, I. A. (2014). The key problem of early diagnosis of risks in banks and the ways of its improvement. Economics and banks, $2,26-33$.

Стаття прийнята

до друку: 20.11.2018 p.

Бібліографічний опис для цитування :

Киевич А. В. Трансформация налоговых систем на примере стран - членов Европейского Союза / А. В.Киевич, И. А Пригодич, И. А. Конончук // Часопис економічних реформ. - 2018. - № 4 (32). - C. 30-37. 